drying period. No temperature rise of particles was observed in these experiments.

There are various interpretations for the reading of a suction thermocouple in fixed and fluidized beds. However, particle concentration in a dispersed bed is lean and the reading of the suction thermocouples shows gas temperature in the bed.

In Eq. (8), the power of the particle Reynolds number, $n$, increases with decreasing void fraction. The amount of particles per unit volume of bed increases with decreasing void fraction, and interference of gas films around the particles occurs. The interference effect between particles increases with decreasing superficial gas velocity, because the gas film increases with decreasing gas velocity. Consequently, no surface areas of the particles act as effective surface area for heat transfer. From Fig. 6, when the void fraction is about one the experimental Nusselt number approximately agrees with the calculated value from the Ranz-Marshall equation.

Heat loss from the bed wall was usually less than $5 \%$ of the heat transfer from gas to particles. The maximum heat loss was about $10 \%$. The effect of heat loss on the calculation of the gas-particle heat transfer coefficient by Eq. (1) is small.

\begin{tabular}{|c|c|c|}
\hline \multicolumn{3}{|c|}{ Nomenclature } \\
\hline$A$ & $=$ cross-sectional area of bed & {$\left[\mathrm{cm}^{2}\right]$} \\
\hline$a$ & $\begin{aligned}= & \text { specific surface of particles per unit } \\
& \text { volume of bed }\end{aligned}$ & {$\left[\mathrm{cm}^{-1}\right]$} \\
\hline$C_{H}$ & $=$ humid heat & $\mathrm{J} / \mathrm{g}$-dry gas $\cdot \mathrm{K}]$ \\
\hline$D_{p}$ & $=$ particle diameter & {$[\mathrm{cm}]$} \\
\hline
\end{tabular}

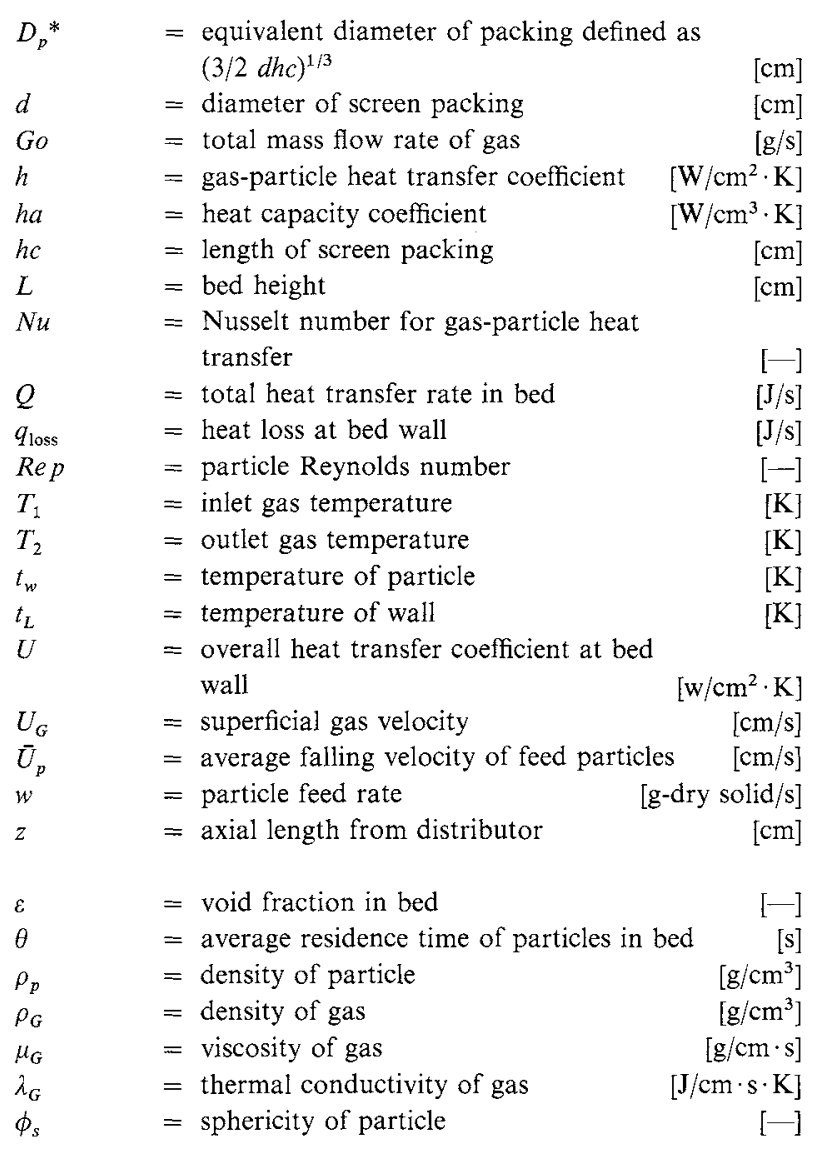

\section{Literature Cited}

1) Ranz W. E. and W. R. Marshall, Jr.: Chem. Eng. Progr., 48, 141 (1952).

(Presented at 47th Annual Meeting of The Society of Chemical Engineers, Japan at Tokyo, March, 1982.)

\title{
RECOVERY OF HEAVY SPECIES BY PULSE GAS DIFFUSION
}

\author{
NORIAKI WAKAO AND SHIGEHARU TANISHO \\ Department of Chemical Engineering, Yokohama National University, Yokohama 240
}

\begin{abstract}
Theoretical calculations were carried out for the separation of light and heavy species in a gaseous mixture. It is shown that a heavy species present in low concentration in a gas is effectively enriched by a batchwise diffusion unit in which the gas is imposed a number of times as a pulse on a porous separating membrane.
\end{abstract}

\section{Introduction}

The objective of this work is, as an extension of the earlier work, ${ }^{1-3)}$ to show with theoretically calculated

\footnotetext{
Received July 3, 1982. Correspondence concerning this article should be addressed to N. Wakao.
}

data that the unsteady-state diffusion process may be successfully employed with a batchwise diffusion unit to enrich a heavier species present in low concentration in a gaseous mixture.

The conditions underlying this diffusion process are that the diffusion should be of Knudsen type and a 
gas is to be imposed on a separating membrane as a pulse. Knudsen diffusion rate is inversely proportional to the square root of the molecular weight of the diffusing species. Therefore, when a gaseous mixture begins Knudsen diffusion through a capillary tube, a light species diffuses faster than a heavier one. Shortly after, the heavier species emerges together with the light species from the tube outlet. This is steady-state diffusion. Even under steady-state conditions, the light species is enriched in a gas diffusing out from the capillary tube outlet. However, the light species is more enriched, compared to that at steady state, in a gas diffused out a short time after the gas imposition. The high enrichment of light species in a gas diffused out of the system, then, means that the heavy species is effectively enriched in the gas remaining in the system.

\section{Theory of Pulse Diffusion}

Suppose a mixture of gas I (light species) and gas II (heavy species) is imposed for a period of time $t_{0}$ on one side (inlet side) of a separating membrane (area $A_{c}$, thickness $L$ and void fraction $a$ ), while the pressure on the other side (exit side) of the membrane is kept almost zero. The mass balance for species I, for example, is given in terms of concentration $C^{I}$ as

$$
a \frac{\partial C^{\mathrm{I}}}{\partial t}=D_{e} \frac{\partial^{2} C^{\mathrm{I}}}{\partial x^{2}}
$$

where $D_{e}{ }^{\mathrm{I}}$ is the effective diffusivity of species I. Under the following conditions:

$$
\begin{aligned}
& C^{\mathrm{I}}=0 \quad \text { at } \quad t=0 \\
& C^{\mathrm{I}}=C_{0}{ }^{\mathrm{I}} \quad \text { at } \quad x=0 \quad \text { for } \quad 0<t<t_{0} \\
& C^{1}=0 \quad \text { at } \quad x=L \text { for } 0<t<t_{0}
\end{aligned}
$$

the solution to Eq. (1) is

$$
C^{\mathrm{I}}=C_{0}{ }^{\mathrm{I}} \Phi(t) \quad \text { for } \quad 0<t<t_{0}
$$

where

$$
\Phi(t)=1-\frac{x}{L}-2 \sum_{n=1}^{\infty} \frac{1}{n \pi} \sin \frac{n \pi x}{L} \exp \left[-(n \pi)^{2} T^{\mathrm{I}}\right]
$$

and

$$
T^{\mathrm{I}}=\frac{D_{e}{ }^{\mathrm{I}} t}{a L^{2}}
$$

The amount of species I extracted from the exit side of the separating membrane while the pulse is imposed on the inlet side is

$$
\begin{aligned}
S^{\mathrm{I}} & =-D_{e}^{\mathrm{I}} A_{c} \int_{0}^{t_{0}}\left(\frac{\partial C^{\mathrm{I}}}{\partial x}\right)_{L} d t \\
& =a A_{c} L C_{0}{ }^{\mathrm{I}} B^{\mathrm{I}}
\end{aligned}
$$

where

$$
B^{\mathrm{I}}=T_{0}^{\mathrm{I}}+2 \sum_{n=1}^{\infty} \frac{(-1)^{n}}{(n \pi)^{2}}\left(1-\exp \left[-(n \pi)^{2} T_{0}^{\mathrm{I}}\right]\right)
$$

and

$$
T_{0}{ }^{1}=\frac{D_{e}{ }^{\mathrm{I}} t_{0}}{a L^{2}}
$$

After time $t_{0}$, either side of the separating membrane is kept at zero pressure so that the pores of the membrane are cleaned:

$$
\begin{aligned}
& C^{I}=C_{0}{ }^{I} \Phi\left(t_{0}\right) \text { at } t=t_{0} \\
& C^{\mathrm{I}}=0 \quad \text { at } x=0 \text { and } x=L \text { for } t>t_{0}
\end{aligned}
$$

The concentration profile of species I in the separating membrane during this cleaning period is then found to be

$$
\begin{aligned}
& C^{\mathrm{I}}=2 C_{0}{ }^{\mathrm{I}} \sum_{n=1}^{\infty} \frac{1}{n \pi} \sin \left(\frac{n \pi x}{L}\right)\left\{\exp \left[-(n \pi)^{2}\left(T^{1}-T_{0}^{\mathrm{I}}\right)\right]\right. \\
& \left.-\exp \left[-(n \pi)^{2} T^{\mathrm{I}}\right]\right\} \quad \text { for } t \geqq t_{0}
\end{aligned}
$$

The amount diffused out from the exit side of the separating membrane over a time from $t_{0}$ to $t$ is

$$
\begin{aligned}
Q_{L} \mathrm{I}(t) & =-D_{e}{ }^{\mathrm{I}} A_{c} \int_{t_{0}}^{t}\left(\frac{\partial C^{\mathrm{I}}}{\partial x}\right)_{L} d t \\
& =2 a A_{c} L C_{0}{ }^{1} \sum_{n=1}^{\infty} \frac{(-1)^{n}}{(n \pi)^{2}} F_{n}{ }^{1}
\end{aligned}
$$

where

$$
\begin{aligned}
F_{n}{ }^{\mathrm{I}}=\exp \left[-(n \pi)^{2} T_{0}{ }^{\mathrm{I}}\right] & +\exp \left[-(n \pi)^{2}\left(T^{\mathrm{l}}-T_{0}^{\mathrm{I}}\right)\right] \\
& -\exp \left[-(n \pi)^{2} T^{\mathrm{I}}\right]-1
\end{aligned}
$$

Similarly, the amount diffused out from the inlet side after time $t_{0}$ is

$$
\begin{aligned}
Q_{0}{ }^{\mathrm{I}}(t) & =D_{e}^{\mathrm{I}} A_{\mathrm{c}} \int_{t_{0}}^{t}\left(\frac{\partial C^{\mathrm{I}}}{\partial x}\right)_{0} d t \\
& =-2 a A_{c} L C_{0}{ }^{I} \sum_{n=1}^{\infty} \frac{1}{(n \pi)^{2}} F_{n}{ }^{1}
\end{aligned}
$$

Equations (1)-(6) are valid for species II if $C_{0}{ }^{\mathrm{I}}$ and $D_{e}{ }^{\text {I }}$ are replaced by $C_{0}$ II and $D_{e}$ II , respectively.

Note that Knudsen diffusivity, $D_{K}$, in a single capillary tube of radius $r_{e}$ is expressed as

$$
D_{K}=\frac{2 \bar{v} r_{e}}{3}
$$

where $\bar{v}$ is the mean molecular velocity given for ideal gas species as

$$
\bar{v}=\sqrt{\frac{8 R_{g} T_{K}}{\pi M}}
$$

in which $R_{g}$ is the gas constant, $T_{K}$ is the temperature and $M$ is the molecular weight of the species. The effective diffusivity of a porous membrane having 


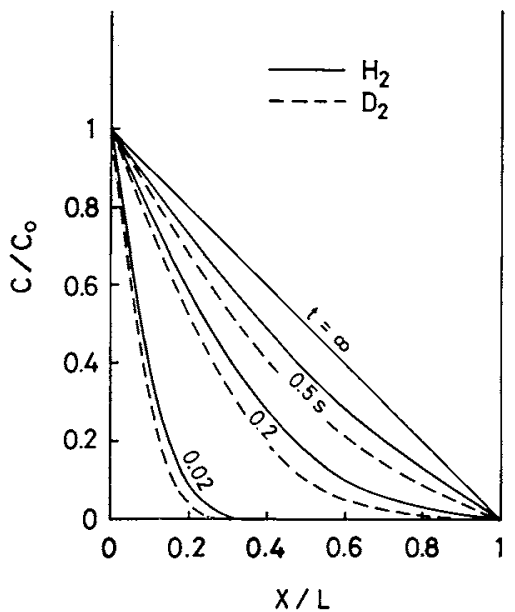

Fig. 1. Concentration profiles in membrane in sequence of time, when a binary gas mixture is imposed on one side of membrane.

pores of radius $r_{e}$, which is small enough so that the diffusion is of Knudsen type, is then

$$
D_{e} \propto \frac{r_{e}}{\sqrt{M}}
$$

For illustration, the concentration profile-time curves for a porous membrane are calculated for the following system:

species I: hydrogen

species II: deuterium

porous membrane: (The membrane is assumed to be identical to porous Vycor glass plate \#7930 of the Corning Glass Works, New York, except that average pore diameter is $40 \mathrm{~nm}$ instead of the $4 \mathrm{~nm}$ for $\# 7930$. The effective diffusivities $D_{e}^{\mathrm{I}}$ and $D_{e}^{\mathrm{II}}$ are estimated from that of hydrogen in porous Vycor glass \#7930 measured at $20^{\circ} \mathrm{C}$ by correcting, with the aid of Eq. (9), for pore diameter or/and molecular weight.)

$$
\begin{aligned}
a: & 0.28 \\
L: & 5.22 \mathrm{~mm} \\
D_{e} \text { I }: & 2.47 \times 10^{-6} \mathrm{~m}^{2} \cdot \mathrm{s}^{-1} \\
D_{e}^{\text {II }}: & 1.74 \times 10^{-6} \mathrm{~m}^{2} \cdot \mathrm{s}^{-1}
\end{aligned}
$$

Figure 1 shows that the light species, hydrogen, penetrates into the porous Vycor glass plate faster than the heavy species, deuterium. It is clear that a gas diffusing out from the exit side of the porous membrane in a short time should be caught in order to attain a high separation efficiency. Figure 2 shows that in a cleaning period the light species diffuses out from the membrane again faster than the heavy species. The total gas removed is shown in Fig. 3 in terms of $1-\left(Q_{0}(t)+Q_{L}(t)\right) /\left(Q_{0}(\infty)+Q_{L}(\infty)\right)$ vs. $t-t_{0}$. The curves indicate that the pores of the membrane are cleaned in about $2.5 \mathrm{~s}$ after the pulse of $t_{0}=$

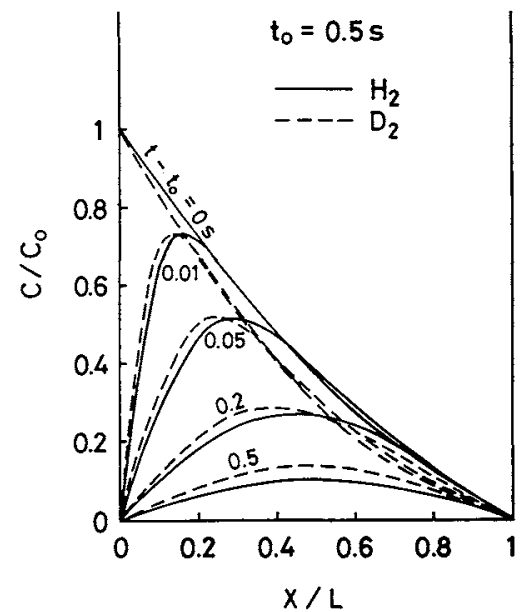

Fig. 2. Concentration profiles in membrane during cleaning period; evacuation from both sides of membrane.

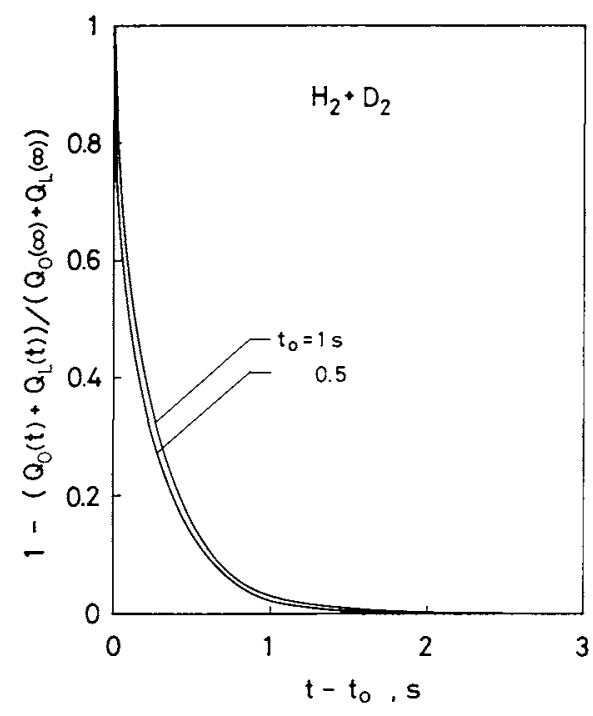

Fig. 3. Total gas removal during cleaning period

\section{$0.5-1 \mathrm{~s}$ terminates.}

\section{Recovery of Heavy Species in Batchwise Con- centrator}

Figure 4 shows the principle of a batchwise concentrator operated based on pulse gas diffusion. The diffusion cell consists of a porous membrane (1) and two chambers (2) and (3) installed on either side of the membrane. Valves (4), (5), (6) and (7) are of solenoid type. First, valves (4), (5) and (6) are closed; valve (7) is opened so that the diffusion cell is evacuated by vacuum pump (8).

\subsection{Gas imposition}

Valve (4) is opened so that gas imposition chamber (2) is filled with gas from reservoir (10). This makes gas imposition on the left side of the porous membrane (1). Gas, rich in light species, diffusing out from the right side of the membrane is continuously removed by vacuum pump (8) 


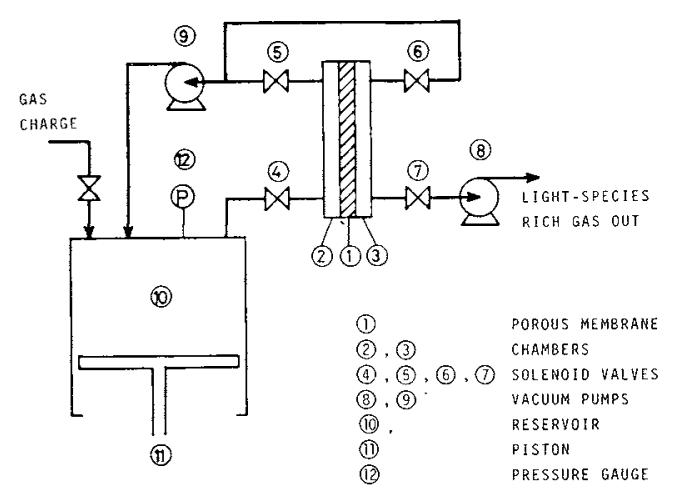

Fig. 4. Schematic diagram of batchwise concentrator.

\subsection{Membrane cleaning}

Valves (4) and (7) are closed and valves (5) and (6) are opened. Gas in the diffusion cell is removed by vacuum pump (9) and fed back to reservoir (10).

If gas imposition on the porous membrane for a period of time $t_{0}$, is followed by membrane cleaning for a time $t_{e}$, the sum of $t_{0}$ and $t_{e}$ is the time required for a single cycle. In fact, a large number of cycles must be applied to extract a considerable amount of light species from the reservoir. In the apparatus shown in Fig. 4, the volume of reservoir (10) is reduced after every cycle (by piston (11)) and the pressure of the reservoir (measured by pressure gauge (12) is kept constant.

The mass balances in the concentrator having a separating membrane of area $A_{c}$, thickness $L$ and void fraction $a$ are given as follows: (Note that reservoir volume $V$ includes the dead volumes of vacuum pump (9) and tubing between the vacuum pump and valve (4). Also, subscript 0 stands for the initial state and $(n)$ for the end of $n$-th cycle.)

Initial:

The amount of species I fed to the concentrator is $V_{0} C_{0}{ }^{\mathrm{I}}$ and that of species II is $V_{0} C_{0}{ }^{\text {II }}$.

First cycle:

The amount of species I removed from the unit during the first cycle is $a A_{c} L B^{\mathrm{I}} C_{0}{ }^{\mathrm{I}}$ and that of species II is $a A_{c} L B^{\mathrm{II}} C_{0}$ II . To keep the pressure of the reservoir unchanged at the initial value, the volume of the reservoir should be reduced after the first cycle to

$$
V_{(1)}=V_{0}-a A_{c} L \frac{B^{\mathrm{I}} C_{0}{ }^{1}+B^{\mathrm{II}} C_{0}{ }^{\mathrm{II}}}{C_{0}{ }^{\mathrm{I}}+C_{0}{ }^{\mathrm{II}}}
$$

The concentration of the light species, for example, in the reservoir after the first cycle is then

$$
C_{(1)}^{\mathrm{I}}=\frac{C_{0}^{\mathrm{I}} V_{0}}{V_{(1)}}\left(1-\frac{a A_{c} L}{V_{0}} B^{\mathrm{I}}\right)
$$

$n$-th cycle:

The amount of species I removed in the $n$-th cycle is $a A_{c} L B^{\mathrm{I}} C_{(n-1)}^{\mathrm{I}}$ and that of species II is $a A_{c} L B^{\mathrm{II}} C_{(n-1)}^{\mathrm{II}}$. The volume of the reservoir is to be reduced to

$$
V_{(n)}=V_{(n-1)}-a A_{c} L \frac{B^{\mathrm{I}} C_{(n-1)}^{\mathrm{I}}+B^{\mathrm{II}} C_{(n-1)}^{\mathrm{II}}}{C_{(n-1)}^{\mathrm{I}}+C_{(n-1)}^{\mathrm{II}}}
$$

The concentration of the light species in the reservoir is

$$
C_{(n)}^{1}=\frac{C_{(n-1)}^{\mathrm{I}} V_{(n-1)}}{V_{(n)}}\left(1-\frac{a A_{c} L}{V_{(n-1)}} B^{\mathrm{I}}\right)
$$

These mass balance equations make it possible to calculate reservoir volume after $n$-th cycle, $V_{(n)}$, and concentrations of species I and II in the reservoir, $C_{(n)}^{\mathrm{I}}$ and $C_{(n)}^{\mathrm{II}}$, respectively.

The calculations are performed for the recovery of a small amount of heavy species using the following batchwise concentrators:

Feed:

A binary gas mixture of $99.9 \mathrm{~mol}$ light and $0.1 \mathrm{~mol}$ heavy species with a molecular weight ratio of ten.

First concentrator:

The gas mixture is charged to the first concentrator, operated with a pulse of $t_{0}=1 \mathrm{~s}$. The initial volume $V_{0}$ of the reservoir is assumed to be such that $V_{0}=100 a A_{c} L$. The effective diffusivity for the light species is assumed to be $D_{e}{ }^{\mathrm{I}}=$ $2.47 \times 10^{-6} \mathrm{~m}^{2} \cdot \mathrm{s}^{-1}$ (the same as in the preceding section). The effective diffusivity for the heavy species, $D_{e}{ }^{\mathrm{II}}=7.81 \times 10^{-7} \mathrm{~m}^{2} \cdot \mathrm{s}^{-1}$, is estimated from the $D_{e}{ }^{\mathrm{l}}$ value by correcting for the molecular weight ratio. The porous membrane is $3.94 \mathrm{~mm}$ thick with void fraction of 0.28 .

Second concentrator:

All the light species-rich gas removed from the first concentrator is charged to the second concentrator. The porous membrane is of the same type as that used in the first concentrator.

Recovery of heavy species:

The heavy species is enriched in the gas remaining in the reservoirs of the first and second concentrators.

The computed data listed in Table 1 show the relationships between the operating conditions of the concentrators and the recovery of the heavy species. It is shown that the binary gas mixture, consisting of $99.9 \mathrm{~mol}$ light and $0.1 \mathrm{~mol}$ heavy species, is reduced to $15.5-18.3 \%$ of the initial volume in an hour, with $94.9-95.0 \%$ heavy-species recovery, in the two concentrators with $8.8-9.8 \mathrm{~m}^{2}$ (total area) of the $3.94 \mathrm{~mm}$ membranes.

This example shows that a small amount of heavy species contained in a gaseous mixture is successfully enriched with batchwise concentrators. This type of concentrator will be most suitably employed where 
Table 1. Recovery of heavy species using two batchwise concentrators operated at constant pressure

Separating membrane: $3.94 \mathrm{~mm}$ in thickness; void fraction 0.28 .

Feed to first concentrator: $100 \mathrm{~mol}$ of a mixture consisting of $99.9 \%$ species I (light) and $0.1 \%$ species II (heavy).

\begin{tabular}{|c|c|c|c|c|c|c|c|c|}
\hline \multirow[t]{2}{*}{$\begin{array}{l}\text { Diffusion } \\
\text { unit }\end{array}$} & \multicolumn{2}{|c|}{ Feed } & \multirow{2}{*}{$\begin{array}{c}\text { Pulse } \\
\text { time } \\
t_{0} \\
{[s]}\end{array}$} & \multirow{2}{*}{$\begin{array}{c}\text { Degas } \\
\text { time } \\
t_{e} \\
{[s]}\end{array}$} & \multirow[t]{2}{*}{$\begin{array}{l}\text { Number of } \\
\text { cycles }\end{array}$} & \multirow{2}{*}{$\begin{array}{c}\text { Running } \\
\text { time } \\
{[s]}\end{array}$} & \multicolumn{2}{|c|}{$\begin{array}{c}\text { Gas } \\
\text { extracted }\end{array}$} \\
\hline & $\begin{array}{c}\text { Species } \\
\text { I } \\
{[\mathrm{mol}]}\end{array}$ & $\begin{array}{c}\text { Species } \\
\text { II } \\
{[\mathrm{mol}]}\end{array}$ & & & & & $\begin{array}{c}\text { Species } \\
\text { I } \\
{[\mathrm{mol}]}\end{array}$ & $\begin{array}{c}\text { Species } \\
\text { II } \\
\text { [mol] }\end{array}$ \\
\hline First & 99.9 & 0.1 & 1 & 2.4 & 225 & 765 & $90.53^{\mathrm{a}}$ & $0.0242^{\mathrm{a}}$ \\
\hline Second & $90.53^{a}$ & $0.0242^{\mathrm{a}}$ & 0.78 & 2.4 & 335 & 1065 & 84.46 & 0.0050 \\
\hline Second & $90.53^{\mathrm{a}}$ & $0.0242^{\mathrm{a}}$ & 0.89 & 2.4 & 265 & 872 & 81.70 & 0.0051 \\
\hline \multirow[t]{2}{*}{$\begin{array}{l}\text { Diffusion } \\
\text { unit }\end{array}$} & \multicolumn{2}{|c|}{ Gas remaining } & \multicolumn{3}{|c|}{ Total gas remaining } & $\begin{array}{l}\text { Recovery } \\
\text { efficiency } \\
\text { of species } I^{\mathrm{b}}\end{array}$ & \multicolumn{2}{|c|}{$\begin{array}{l}\text { Membrane area needed to process } \\
100 \text { mol-feed in an hour }\end{array}$} \\
\hline & $\begin{array}{c}\text { Species } \\
\text { I } \\
{[\mathrm{mol}]}\end{array}$ & $\begin{array}{c}\text { Species } \\
\text { II } \\
{[\mathrm{mol}]}\end{array}$ & & $\begin{array}{c}\text { Species } \\
\text { I } \\
{[\mathrm{mol}]}\end{array}$ & $\begin{array}{c}\text { Species } \\
\text { II } \\
{[\mathrm{mol}]}\end{array}$ & {$[\%]$} & $\begin{array}{c}A_{c} \\
{\left[\mathrm{~m}^{2}\right]}\end{array}$ & $\begin{array}{l}\text { Total area } \\
\qquad\left[\mathrm{m}^{2}\right]\end{array}$ \\
\hline First & 9.37 & 0.0758 & & & & & 4.31 & \\
\hline Second & 6.07 & 0.0192 & & 15.44 & $0.0950^{\mathrm{c}}$ & 95.0 & 5.44 & 9.75 \\
\hline Second & 8.83 & 0.0191 & & 18.20 & $0.0949^{c}$ & 94.9 & 4.45 & 8.76 \\
\hline
\end{tabular}

a The gas extracted from first diffusion unit is charged to second diffusion unit for further recovery of heavy species.

$b$ Recovery efficiency is defined as total amount (c) of species II remaining in first and second diffusion units divided by amount $(0.1 \mathrm{~mol})$ of species II charged to first diffusion unit.

not a large amount of gas is to be processed. Also, the concentrator may be used not only for the recovery of heavy species, as demonstrated in this work, but for recovery of light species as well.

\section{Nomenclature}

$\begin{array}{ll}a & =\text { void fraction of membrane } \\ A_{c} & =\text { membrane area } \\ C & =\text { concentration } \\ C_{0} & =\text { initial concentration } \\ D_{e} & =\text { effective diffusivity } \\ D_{K} & =\text { Knudsen diffusivity in a capillary tube } \\ L & =\text { membrane thickness } \\ M & =\text { molecular weight } \\ r_{e} & =\text { radius of capillary tube or pore } \\ t & =\text { time } \\ t_{e} & =\text { cleaning time } \\ t_{0} & =\text { pulse time } \\ T & =\frac{D_{e} t}{a L^{2}}\end{array}$

$\begin{array}{rlrl}{[-]} & \langle\text { Superscripts } & \\ {\left[\mathrm{m}^{2}\right]} & \text { I } & =\text { light species } \\ {\left[\mathrm{mol} \cdot \mathrm{m}^{-3}\right]} & \text { II } & =\text { heavy species } \\ {\left[\mathrm{mol} \cdot \mathrm{m}^{-3}\right]} & & \\ {\left[\mathrm{m}^{2} \cdot \mathrm{s}^{-1}\right]} & \langle\text { Subscript }\rangle & \\ {\left[\mathrm{m}^{2} \cdot \mathrm{s}^{-1}\right]} & (n) \quad=n \text {-th cycle }\end{array}$

\section{Literature Cited}

1) Wakao, N.: Nature, 278, 35 (1979)

2) Wakao, N.: Nuclear Eng. and Design, 55, 145 (1979).

3) Wakao, N., K. Suzuki and M. Ishiko: J. Chem. Eng. Japan, 14, 164 (1981). 